\title{
An Ecologically Intensive Approach for the Design of Sustainable Horticultural Systems in the Tropics
}

A. Ratnadass, P. Deberdt, P. Fernandes, I. Grechi, B. Rhino, P. Ryckewaert \& E. Malézieux UR HortSys, Centre de coopération internationale en recherche agronomique pour le développement, F-34398 Montpellier, France cirad

Fruit and vegetable growers in the tropics are faced with plant protection issues resulting in food insecurity and low-income in low-input traditional agrosystems (e.g. in the Sudano-Sahelian zone of Africa), and pesticide-induced adverse impacts on human health and the environment in intensive systems (e.g. in French overseas islands). Setting up an "ecologically intensive" horticulture by modifying agrosystems to mobilize natural regulation mechanisms according to the scientific principles of agroecology, has therefore become a major challenge.

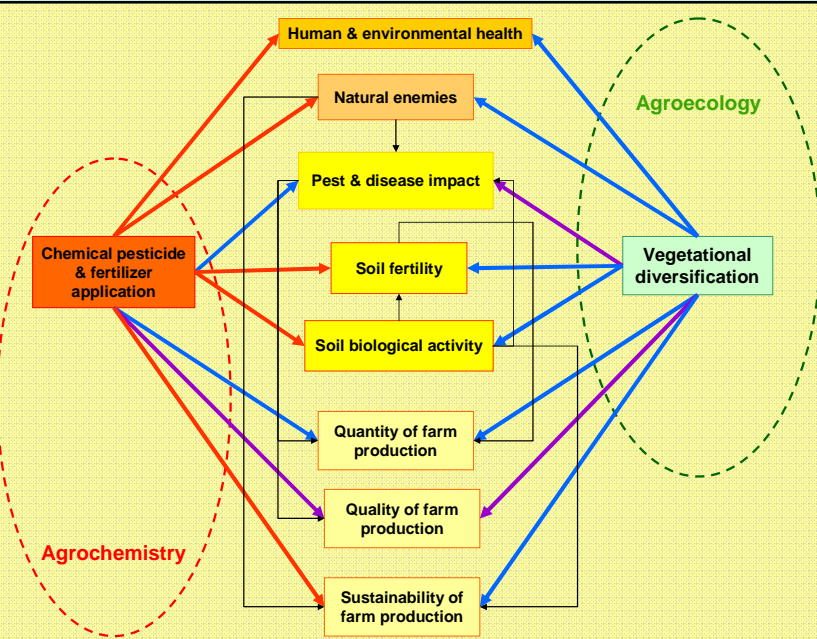

The planned introduction and management of plant species diversity (PSD) is the most promising way of breaking with "agrochemistry" and moving to "agroecology" [1].

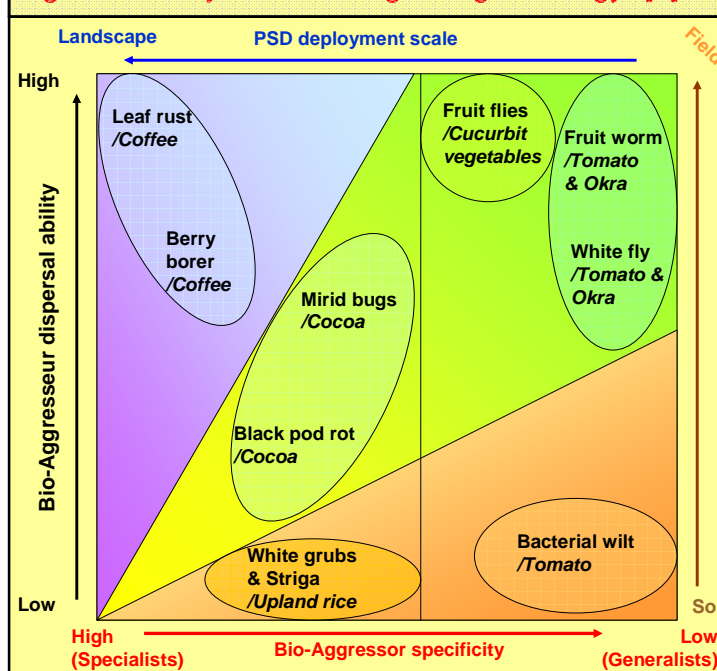

The Cirad Omega ${ }^{3}$ project [3] builds on case studies taken in tropical cropping systems, representing a broad range of PSD levels, scales and deployment modalities, according to a typology of pests and pathogens based on life-history traits the most amenable to manipulation by PSD.

After formalizing the ecological processes studied, results on case studies on generalist vs specific pests \& pathogens with low vs high dispersal ability, will provide decision-making rules which will help set up mechanistic models to predict the impact of PSD plants \& deployment modes on pests \& pathogens with similar life-history traits. Existing models can also be used with adequate parameterization: e.g. individual-based models for the push-pull effects on TFW at the field/immediate neighboring levels, and differential equation-based models for allelopathic effects on Ralstonia at the soil/field level.

References: [1] Deguine et al, 2008. Protection des cultures: De lagrochimie a l lagroécologie. Versailles, France: Quae; [2] Malézieux et al., 2009. Agron. Sustain. Dev. 29, 43-62, [3] Ratnadass, A. et al. 2008 Proc.Endure International Conference: Diversifying crop protection, $12-15$ Oct 2008, Grande-Motte, France Pigeon Pea $>$ Sorghum $>$ Cotton $>$ Sweet corn

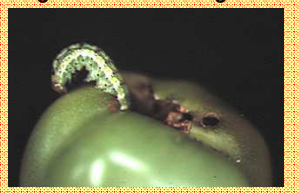

In Martinique, in terms of Sweet corn cultivar attractiveness for TFW on tomato and « dead-end » potential: Sugar $>$ Java $>$ Challenger

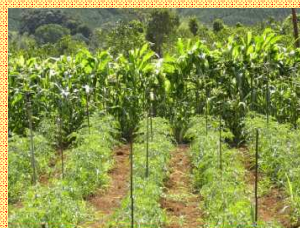

In Martinique, 6 plant species/cultivars were selected based on host status, potential for Multiplying Ralstonia solanacearum populations in the rhizospheric soil, anti-microbial effect and agronomic performance:

- Raphanus sativus

- Mucuna deeringiana - Crotalaria juncea CV-IAC1 - Crotalaria spectabilis

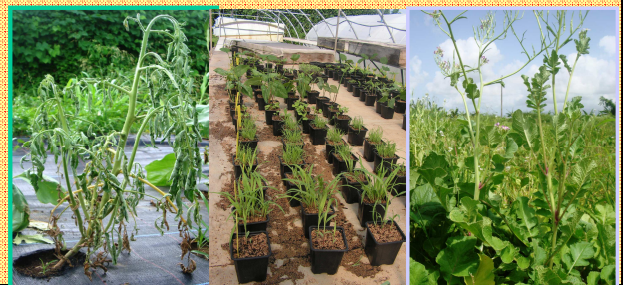

Horticultural cropping systems, which are basically multispecies-based, provide ideal frameworks for studying the impact of PSD on pest and

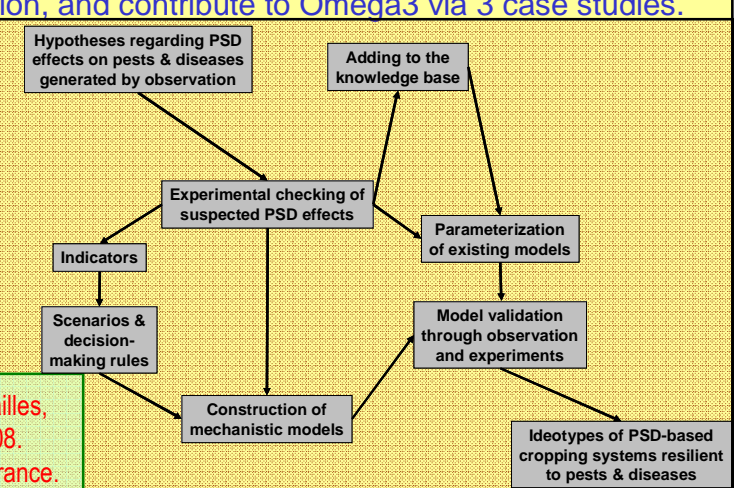

